\title{
Design and Implementation of Smart Energy Meter System with GSM Module
}

Md Riyad Hossain ${ }^{\mathrm{a}}$, Haimanti Biswas ${ }^{\mathrm{b}}$, Abu Raihan Diderc, Dr. Sheshang Degadwala ${ }^{\mathrm{d} *}$

aUG Scholar, Electronics \& Communication Engineering, GH Patel College of Engineering \& Technology, VV

Nagar, Anand, India

bUG Scholar, Information technology, Sigma Institute of Engineering, Vadodara, India

cUG Scholar, Electrical Engineering, VVP Engineering college ,Rajkot, India

dAssociate Professor \& Head of Department, Computer Engineering Department, Sigma Institute of Engineering, Vadodara, India

\begin{abstract}
Article Info

Volume 7, Issue 6

Page Number : 51-60

Publication Issue :

November-December-2020

\section{Article History}

Accepted : 01 Nov 2020

Published : 07 Nov 2020

Automated Meter reading systems are an invaluable technological advancement that can lead to a better standard of living, owing to the fact that metering has become a part and parcel of our mundane lives. It solves many issues of the traditional meter reading system like need for human resources, efficiency, accuracy, delayed work, unavailability of customer during metering visit by employee, etc. Moreover it is more economical and helps to save energy in a more efficient and effective way. Furthermore it has a very notable advantage of having the ability to predict the energy demands of the future, starting from every household to the entire planet. The main objective of the smart energy meter is to not only measure the consumer's power consumption but also to transmit the readings of the meter to utility office every week/day/hour with the help of GSM module or by uploading it onto the cloud. Readings of the meter will be taken out using Rs485 Module and will be given to Raspberry pi and transmitted further to utility office with the help of GSM module or by uploading it onto cloud and at the same time consumption in terms of units as well as rupees will be transmitted to consumer which they can access in SMS or application. Electrical power has become indispensable to human survival and progress which leads to the enhancement of the people's standard of life by the introduction of automation in to energy distribution and management. With the constant development in technology, the need of automated meter reading systems is also increasing.it is basically Raspberry pi based operational system. The technology of e-metering (Electronic Metering) has gone through rapid technological advancements and there is increased demand for a reliable and efficient Automatic Meter Reading (AMR) system.

Keywords : Raspberry Pi, Google Cloud, Design Analysis, E-Metering, GSM module, Automatic Meter Reading (AMR) system.
\end{abstract}




\section{INTRODUCTION}

The traditional meter reading process involves using the analog meters to collect the data of the energy consumed and display it either on a number dial or a digital display. The service provider person comes to the place of the meter and notes down the reading at the end of every billing cycle. But the traditional meter reading process not only wastes labor human power, but also is error prone. The procedures of sending the bills to customer are very laborious and cumbersome. The conventional process is time consuming as well. Another major problem in this system is that the readings cannot be taken if no one is available at the home or where the meter is located. The current system does not provide any scope for the user to conserve energy or does it provide energy consumption predictions for near future that enables the user to act in a more planned way. There are many such problems that cause inconvenience to the power provider as well as the consumers. Even though the conventional meters were replaced with more efficient electronic energy meters these problems still persists. unconventional approaches have been developed recently, including safety system conversion, i.e., Conversion of manual safety system to autonomous safety system.

\section{LITERATURE REVIEW}

Pratik,teshpang ,Mongpati (1) , proposed energy meter system (EMS) transmits data like consumed energy in $\mathrm{kWh}$ and generates a bill over a GSM mobile network. Other advantages include that the system provides domestic power consumption accurately, safely and with a relatively fast update rate. Keywords-SMART energy meter, mircocontroller, GSM short message service (SMS), energy meter system (EMS), remote access, direct current (DC), alternating current (AC)
Brinda,Vishal, Jaladi (2), proposed a model electricity meter reading for electricity usage and billing is done by human workers from home to home and building to buildings. The purpose of this project is to develop a Smart Electricity meter using GSM. This can reduce human errors and helps to retrieve the real time meter value via GSM and send it to customers mobile phone through GSM. This also allows electricity board to modify the variable package price in specific duration. The administrator can analyse the customers power consumption data and generate the report from the data online. The prototype will be able to introduce the billing system to the customers, get the power consumption data from smart meter, keep the data in centralized database and generate the report.

Zahid Iqbal, M. Wasim, Tahir Mahmood,(3) An automatic remote meter-reading system based on GSM is presented in this paper. This paper is useful to obtain meter reading when desired so meter readers don't need to visit each customer for the consumed energy data collection and to distribute the bill slips. Microcontroller can be used to monitor and record the meter readings. In case of a customer defaulter, no need to send a person of utility to cutoff the customer connection. Utility can cut off and reconnect the customer connection by short message service (SMS). Furthermore, the customer can check the status of electricity (load) from anywhere. In this system energy meter readings are being transferred by making use of GSM.

Sneha choudhury, Ashfaq Sheikh, Purvang rathod, (4) developed a model This paper presents a smart energy meter for an automatic and superior metering and billing system. The integration of the Raspberry pi and GSM Short Message Service (SMS) provide the meter reading system with some automatic functions that are predefined. The proposed energy meter system can incorporate with embedded controller and 
GSM modem to transmit the data like consumed energy in $\mathrm{kWh}$, generated bill, services (line Cut/On) over GSM mobile network such as data can be then fed and integrated into existing energy management systems located at power companies or organizations to provide the services among the customers without man-power.

Rosario Morello, Lipari, Lugara (5) proposed it as immediate to conclude that an efficient distribution of energy must necessarily bring into account the energy footprint of the area, because the energy transport should be always as short as possible, to minimize losses and maximize the efficiency of the network. This concept is the core of the smart-grid idea, on which the global scientific community is investing heavily in research, the idea is a power distribution grid, based on the experience in the information and communications technology field, which can route the energy through appropriate algorithms that are able to determine the optimal path. Of course, behind all this there must be a network structure capable of acquiring detailed data from widespread production and consumption of energy and make them easily available along with additional information

Chiamaka Lizama,(6) build a theoretical proposal Smart metering is a major development in utility industries today especially the electricity industries. However, many benefits of smart metering have not been fully explored due to the limited functions of many prepaid meters that have been implemented so far in most developing countries. With the spread of internet use and web based application [1], there is the need to focus on how prepaid meters can be aided to stay online through Mobile Communication Systems

Pravin Vadda(7) proposed a model of smart metering which state that The main drawback of previously used traditional meters is that they do not provide information to the consumers, which is accomplished with the help of Smart Meter. A Smart Meter helps consumer to know the information of consumption of electricity for appliances in their respective houses. The aim of this research work is to measure and analyze power consumption using Smart Meter data by conducting case study on various households.

Masudur Rahman,Noor E Zannat, Ohidul Islam(8) give a theoretical propose which state that, Every management system is trying to make automatic, portable and remote control. This work presents a novel smart energy meter for an automatic and superior metering and billing system. The integration of the raspberry pi and GSM Short Message Service (SMS) provide the meter reading system with some automatic functions that are predefined.

Based on this literature review, it can be concluded that safety system of metering has a great effectiveness for upcoming use. A comprehensive research has been performed to select different material, method and designing of different safety system that offer features such as productivity,eco friendly, economical produced base in a large scale and benefit for users. Conceptual task has been performed on the provision of safety system and theoretical expressions introduced, based on ideal assumptions. The proposed technique figured out new factors for design of an effective safety system. The Knowledge with respect to the factors governing for safety system is beneficial for the society and accordingly, suitable modifications are introduced into the proposed model. Their effects on the using and efficiency are plotted for the proposed system. 


\section{DESCRIPTION OF WORKING PROCESS}

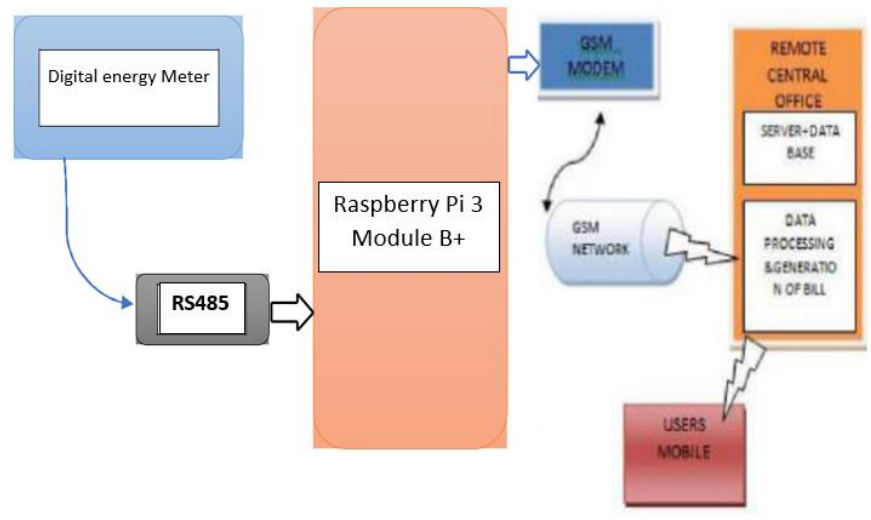

Figure(a): Block diagram of Smart Digital Metering System

Digital Energy Meter is connected to Raspberry Pi module via RS485 Module. RS485 is used to fetch data from the meter, it is a communication bus which facilitate the communication between meter and Raspberry $\mathrm{Pi}$ Module. Raspberry $\mathrm{Pi}$ is further connected with the GSM module. Sim card is inserted in the GSM module which helps to connect with the GSM network. Data is sent to remote central office over GSM network. Data processing as well as generation of bill takes place at central office and then transmitted to users mobile.

Design Thinking is a methodology used by designers to solve complex problems ,desirable solutions for users. Design Thinking draws upon logic, imagination, intuition, and In this work, systemic reasoning, to explore possibilities of what could be, and to create desired that benefit the end user. A design mind-set is not problem-focused, its solution focused, and action oriented. It involves both analysis and imagination The body formation of device related with metering operation incorporated with frame designing appropriation of components. After building the model of device in software we have elected different hardware parts like connecting wires, Raspberry Pi 3 module B+,GSM Modem (GSM network)Digital Smart Meter, User mobile. The part which we elected for device, some of the parts we have purchased online and rest of them we bought from local shop. After collecting all of the parts, initially we structured and make a architectural design for settle down all the other parts orderly. Secondly, we have assembled them robustly with the glue for giving strength and clip in a manner that it cannot fall off. We have designed the device in a way that it can carry the whole part of structure etc. Once the assembly is done, now we dealt with most significant part of the project which is synchronizing all the part then that can give a moderate output of operation.

\section{WORKING OPERATION OF SMART DIGITAL ENERGY METER SYSTEM}

\section{Interfacing}

\section{Software installation}

Download the Required Software and Files

- Get the SD Card and the Card Reader

- Check the Drive in Which the SD Card Is Mounted

- Format the SD Card

- Write the OS on the S D Card

- $\quad$ Eject the SD Card

- $\quad$ Put the microSD card in your Pi and boot up

- Install xrdp command to access Pi Remotely

To connect Raspberry pi Remotely

Configure the Raspberry pi

- $\quad$ set the raspberry pi os time

- change the password of the Raspberry pi

- connect the raspberry pi serially

\section{Connection between raspberry pi module and GSM Module}

- Install minicom to check GSM Communication 
- Now again open Terminal and install minicom to check communication between raspberry pi and GSM module

Following steps shows the steps to make necessary changes in minicom

Type Sudo Minicom on terminal window

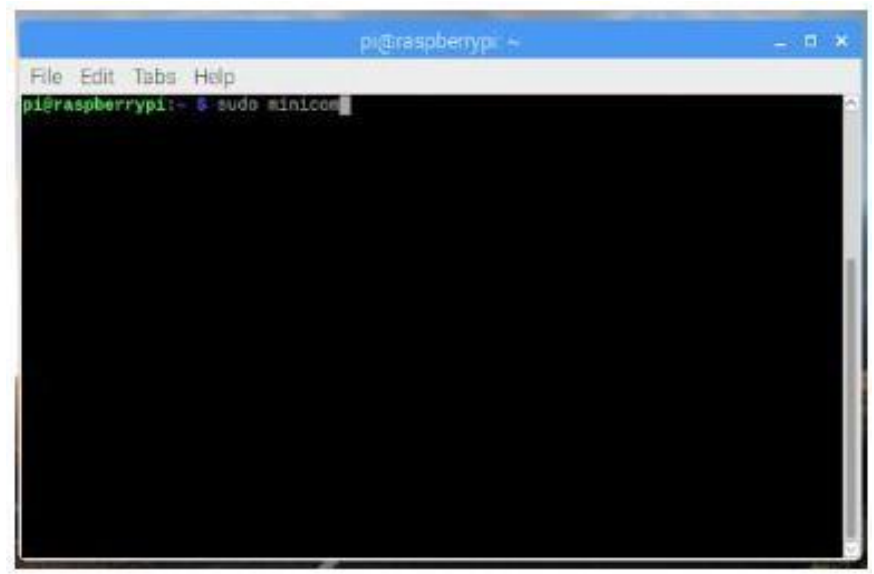

Fig a. Sudo Minicom terminal window

- Below Window will get appear

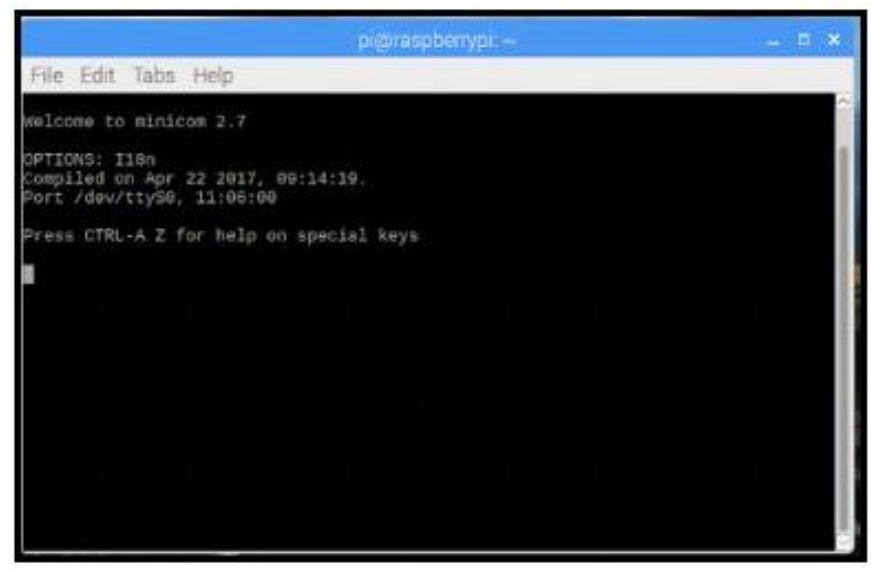

Fig b. Sudo Minicom terminal window

- By default, when we connect GSM module to raspberry-pi controller board through USB to Serial connector then automatically minicom shows Port /dev/ttyUSB0. But, when we want to connect GSM serially with pi then we have to change port name from ttyUSB0 to ttyS0
- For that

- press CTRL+A

- It will show a Menu shown in below image

- Select Serial port setup from that menu

- Change port name from ttyUSB0 to ttyS0

- Change Baud rate 115200 or 9600

- Press Enter

- Press Set default as df1

- Press Exit

- Press CTRL+A

- Press X

- Press Enter

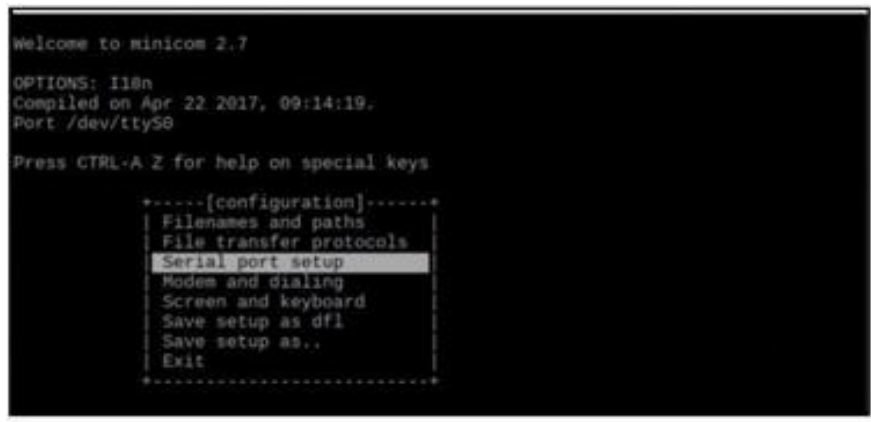

Fig c. Sudo Minicom terminal configuration window

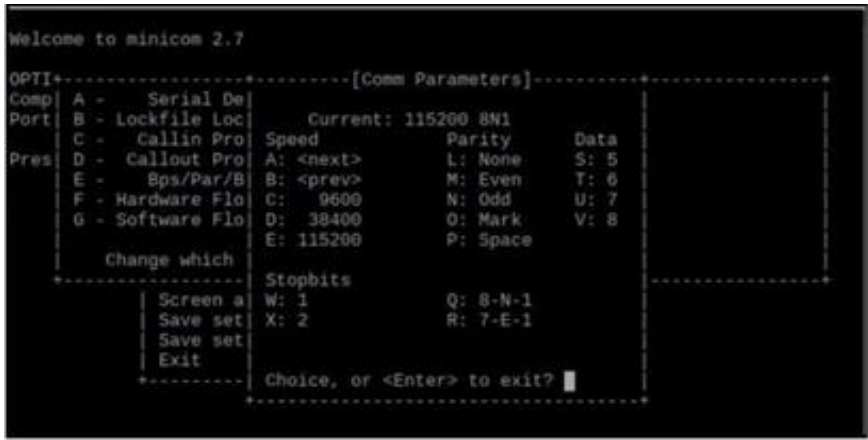

Fig d. Sudo Minicom terminal configuration window 


\section{Mobile Application}

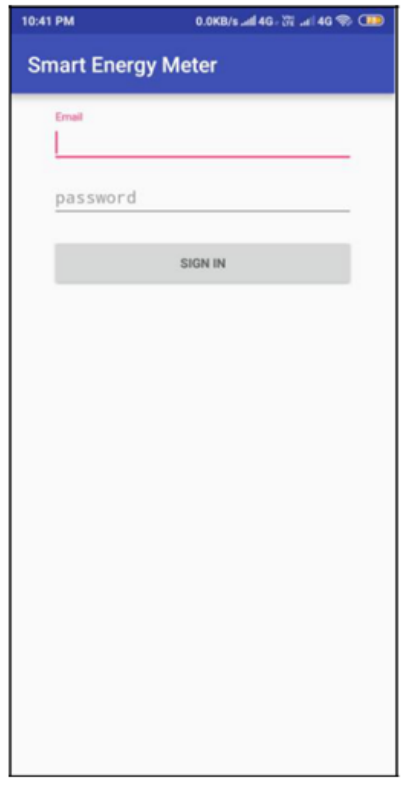

Fig e. Sudo Minicom

terminal configuration

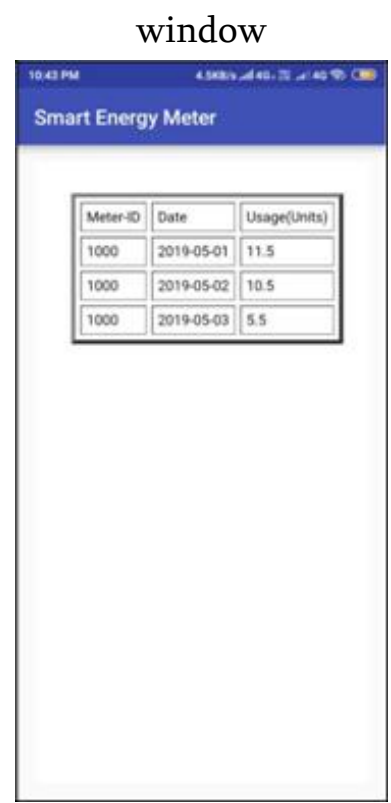

Fig g. Tabulation of representation of the data received

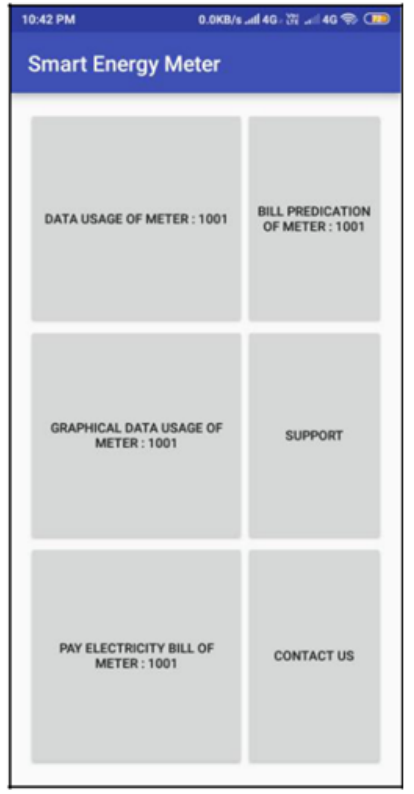

Fig f. Application main window

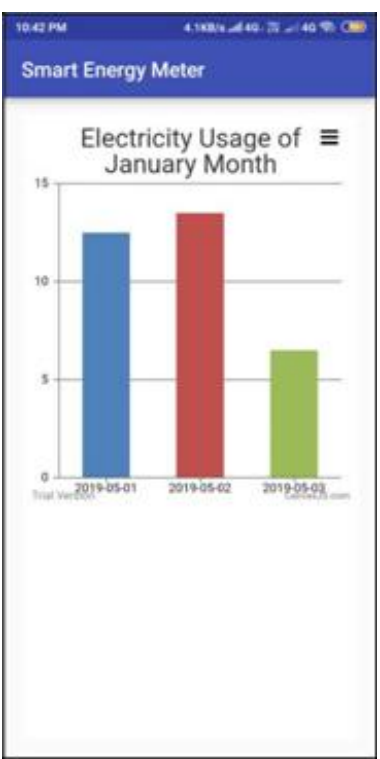

Fig h. Graphical representation of the data received

This kind of real time data collected from each of the individual houses is really a boon to data scientists, who use machine learning and data mining tools to build a predictive model over this valuable data to predict the future energy demands starting from

every single house, area, city to the entire planet. Thus leading to sophisticated and predictive energy production, conservation and management.

\section{WORKING OPERATION IN FLOW CHART OF DIGITAL SMART METER}

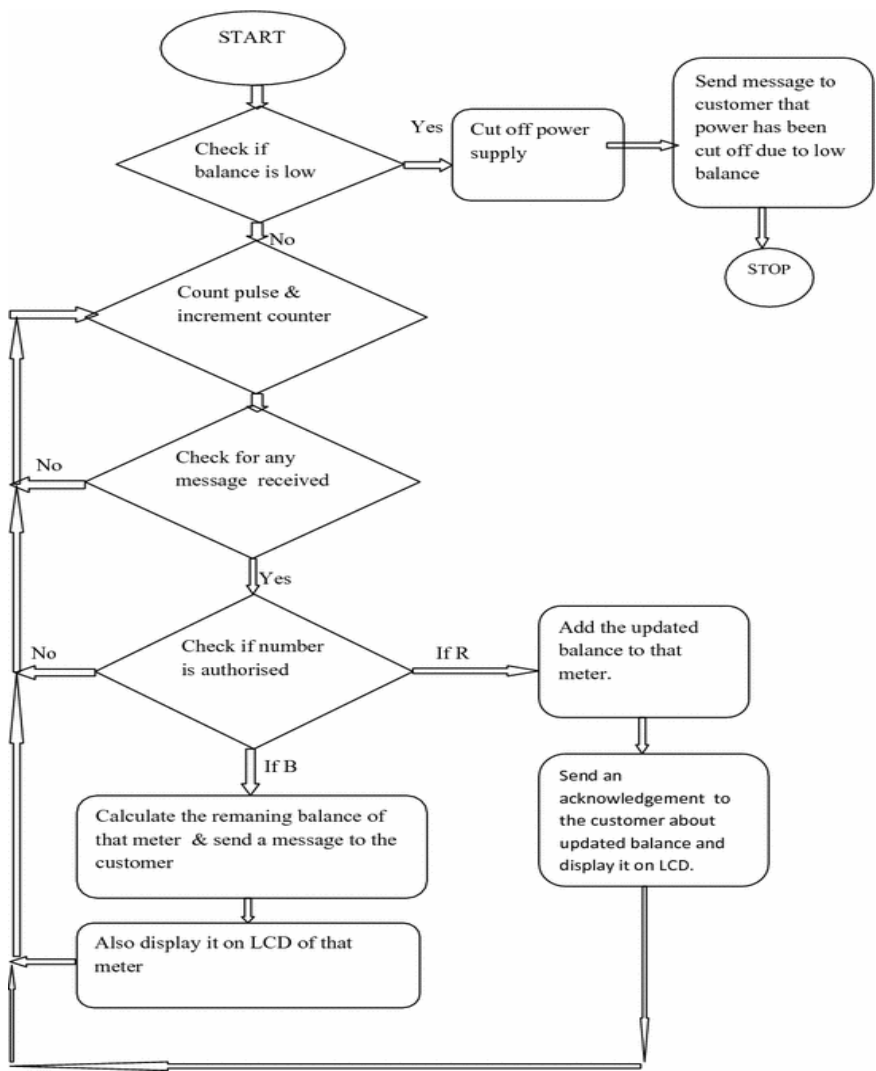

Figure(b): Flowchart of working of Digital Smart

\section{Meter}

This flowchart shows that ho to operation will be done by the device by using, GSM module for sending notification to users as that taking effective action for chasing reading as well as better functional operation.

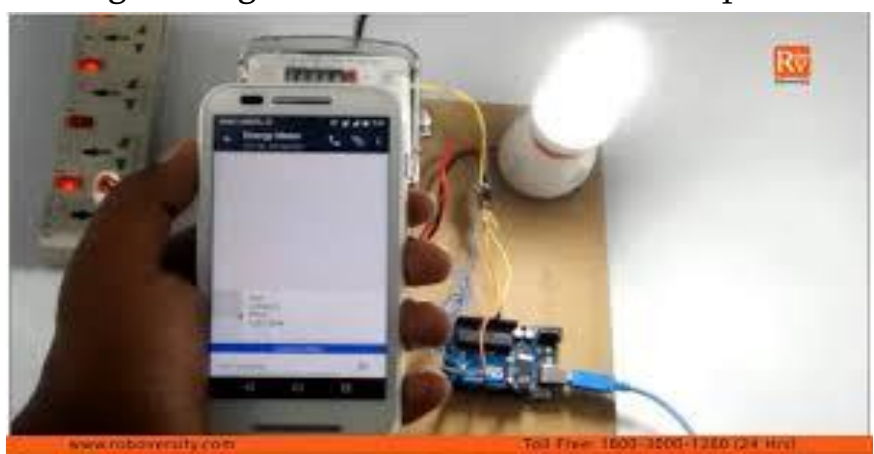

Figure(c): Working of Digital Smart Meter System 

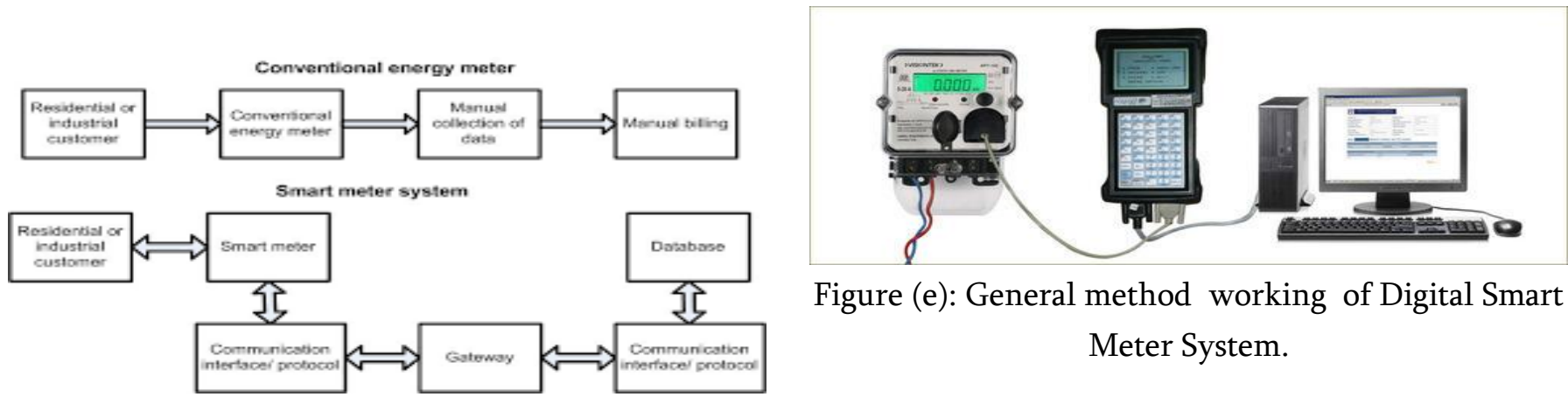

Figure (e): General method working of Digital Smart

Figure(d): Difference between conventional and

smart meter system

Meter System.

\section{EXPERIMENTAL SETUP AND PROCEDURE}

Experiments were performed using Digital energy meter by L\&T, GSM Module,RS485,Ruspberry Pi. The detail and specification of components of this project is given in a tabular form:

\begin{tabular}{|c|l|l|}
\hline Components Name & \multicolumn{1}{|c|}{ Specifications } \\
\hline $\begin{array}{r}\text { Digital Energy Meter by } \\
\text { L\&T }\end{array}$ & $\begin{array}{l}\text { It has 14 digital pins (6 analog } \\
\text { pins, 6 are used for PWM } \\
\text { outputs) } \\
16 \text { MHz ceramic resonator } \\
\text { It has a USB cable, a power } \\
\text { jack port } \\
\text { It accepts voltages between 7 } \\
\text { and 20 volts } \\
\text { It can be connected by a USB } \\
\text { cable which is used for power } \\
\text { supply or 9V external battery } \\
\text { can be used. Brand: L\&T } \\
\text { Model Name/Number: ER300P } \\
\text { Connection Size: } 3 \text { Phase } 4 \\
\text { Wire } \\
\text { Operating Temperature: }-10 \text { to } \\
+55 \text { Deg C } \\
\text { Frequency Display: 50Hz } \\
\text { Accuracy Class: Cl 0.5S }\end{array}$ \\
\hline
\end{tabular}




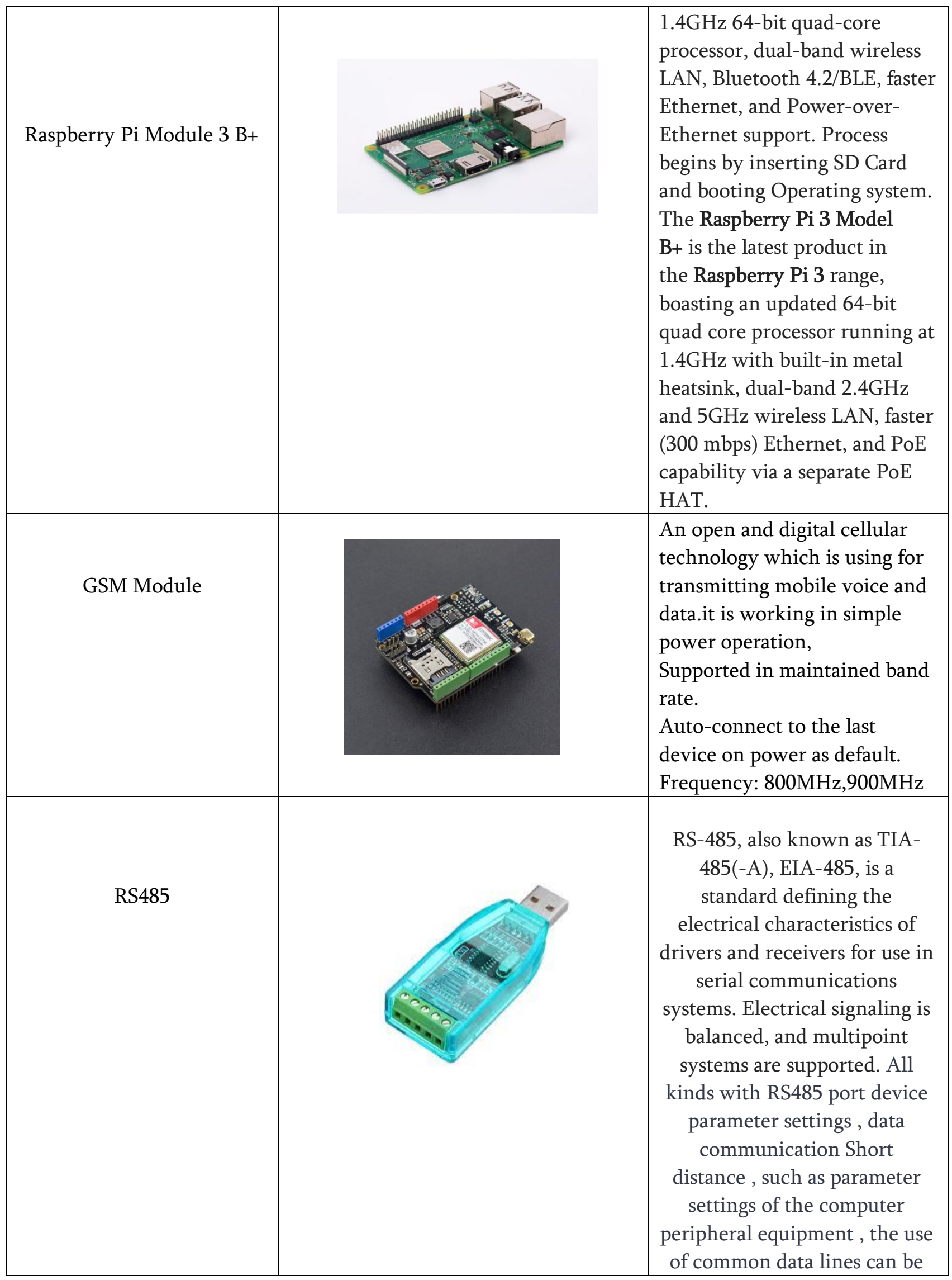


The system can be monitored by using mobile phones. Here we have used GSM module which can defined as a chip or circuit that will be used to establish communication between a mobile device or a computing machine and a GSM or GPRS system. A GSM modem is a wireless modem that works with a GSM wireless network. A wireless modem behaves like a dial-up modem. The main difference between them is that a dial-up modem sends and receives data through a fixed telephone line while a wireless modem sends and receives data through radio waves. The most obvious advantage of GSM is its widespread use throughout the world. According to Gsmworld.com, GSM has a harmonized spectrum, which means that even though different countries may operate on different frequency bands, users can transfer seamlessly between networks and keep the same number. As operation of GSM will turn on for notify users to giving information throughout massaging as requirement or demand of situation.

\section{VII.FACTOR CONSIDERATION DURING THE DESIGN}

\section{Well Maintained Environment}

At the time of designing and make structural function for getting benefited outcome, well maintained environment is needed for better output of result. The meter should be well maintained with sufficient effort, and all functional parts should be well sound maintained. The outcome where work will be reflected should be fulfilled all that conditions.

\section{Good Efficiency}

All that efficiency will depend upon the proper connection as well as order nomination of all parts of device that can give a good result with ensure of betterment.

Eco-Friendly
The device working process is very much eco friendly there is no collision in between components and the safe has been ensure for users.

\section{RESULT AND DISCUSSION}

\section{Problems Faced}

Working with Raspberry $\mathrm{Pi}$ is quite sensitive. Interfacing digital energy meter is has to be connected carefully. After searching a lot and then came to know about the availability of communication Modbus named RS485 and used it in project. Interfacing GSM module also took lot of time, studying AT commands, implementing commands etc. Most challenging task was to design a mobile application as it is out of our domain and it required lot of patients and coding to develop single mobile application.

\section{FUTURE SCOPE}

Though many have tried implementing a country wide Smart Energy Meter, it is still an unreachable goal, many factors like cost, feasibility and mainly the need to replace the existing system have hindered its development. At least in near future, the cost involved in the building of this system could be minimized by using more efficient technology and commercializing it by production in a large scale thus reducing the production costs tremendously and hence making it more feasible to be implemented worldwide. The system could be made smarter by allowing the user to check for the power consumption and alert him on his power consumption and also allows him to turn off the various devices from his mobile application itself hence conserving energy and saving money. Moreover if real time data feeds of the energy usage were tracked and stored in a centralized data centre it will enable the government or the energy provider to predict the energy demand trends consequently 
ensuring uninterrupted supply of electricity and reducing the unexpected load on the electricity grid making it more tolerant to failures.

The system of digital smart meter device considers the time and utilization cover by device in a decent large society. various factors are considered when it sated in different location of different society.

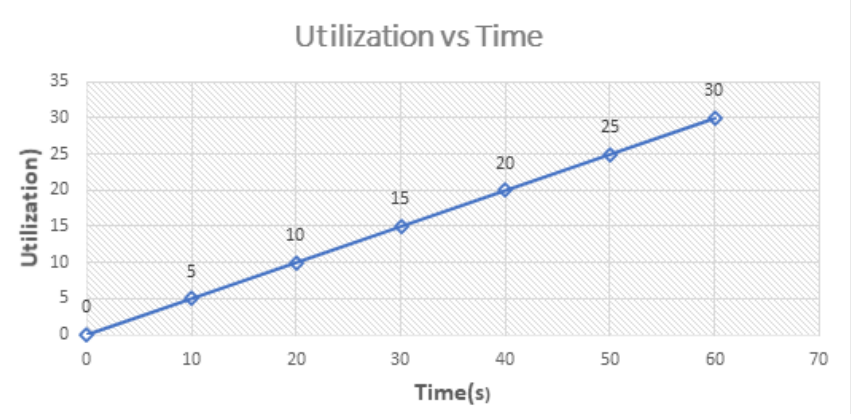

Figure(f): Utilization vary with time (Basis of Response )

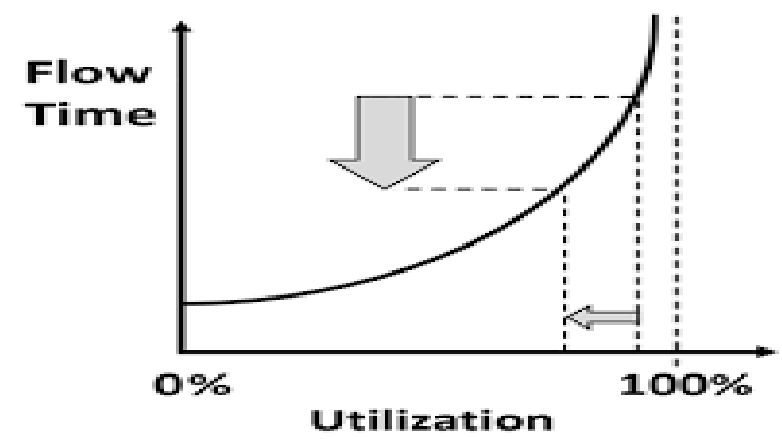

Figure(g): Utilization vary with flow time (Response )

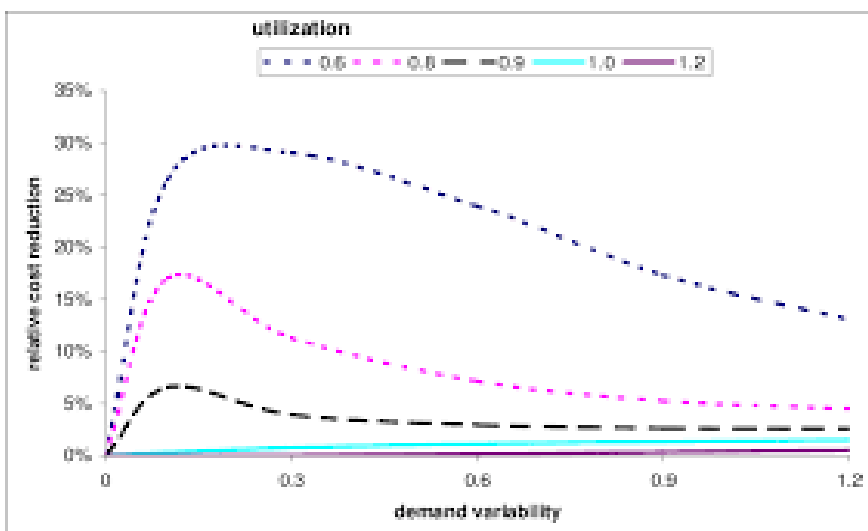

Figure(h):Error graph has been made for Utilization vary with time (Basis of Response )

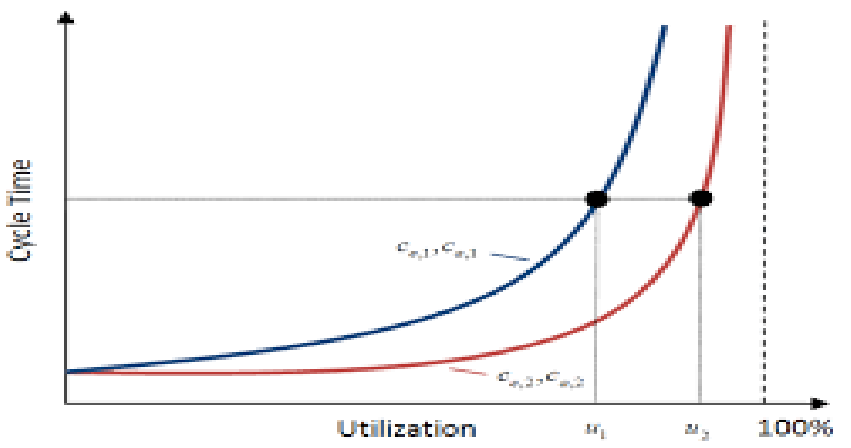

Figure(i): Generalized graph which is the basis of long term result analysis of Utilization vary with time

The graph fairly demonstrates that when the time is increasing the utilization covered by the device is also increased.

Several problems and factors related to design, selection of equipment and their application were confronted during the process of implementation of the device. In this section, the accomplishment of the proposed or introduced problem should be entertained by users as per requirement.

\section{CONCLUSION}

Based on this study of smart metering using automation system, the following limitations can be drawn:

Based on the performance criteria considered, several systems where compared and now we come to a conclusion that, when it comes to Reliability and Feasibility GSM topped the charts. Other suggestion would be to include a web/mobile interface that gives a real-time feedback of the energy consumption, maybe even give the amount of energy consumed by every device in every room and also give energy conservation tips too, based on the data obtained. The real-time data thus obtained can also be used to build a prediction model over it, for predicting the energy demands trends of the future, over any given time period. 


\section{REFERENCES}

[1]. Smart_Energy_Meter

https://www.researchgate.net/publication/33403201

7_Smart_Energy_Meter

[2]. Smart Energy Meter https://ijesc.org/upload/305361fdfe4f4aa6a9b0ad0b0 3bbec73.Smart\%20Energy\%20Meter.pdf

[3]. Automatic_Energy_Meter_Reading_using_Smart_E nergy_Meter

https://www.researchgate.net/publication/27714143

6_Automatic_Energy_Meter_Reading_using_Smart_ Energy_Meter

[4]. Smart Energy Meter using GSM and Arduino https://ieeexplore.ieee.org/document/8300772

[5]. A smart Energy meter for Power Grid https://ieeexplore.ieee.org/document/6860868

[6]. Smart_Energy_Meter_for_Load_Control_using_Mo bile_Communication_Technology https://www.researchgate.net/publication/32401383 7_Smart_Energy_Meter_for_Load_Control_using_M obile_Communication_Technology

[7]. Smart Metering for Smart Electricity Consumption https://www.diva-

portal.org/smash/get/diva2:829754/FULLTEXT01.pdf

[8]. ARDUINO AND GSM BASED SMART ENERGY METER FOR ADVANCED METERING AND BILLING

SYSTEM

https://ieeexplore.ieee.org/abstract/document/73074

98

[9]. H.G.Rodney Tan,IEEE, C.H.Lee and V.H.Mok, IEEE

, "Automatic Power Meter Reading System Using GSM Network", The 8th International Power Engineering Conference ,pp.465-469,IPEC 2007.

[10]. Ashna. K,Sudhish N George, "GSM Based Automatic Energy Meter Reading System with Instant Billing", 978-1-4673-5090-7/13@2013 IEEE, pp 65-71.

[11]. H. M. Zahid Iqbal ,M.Waseem,Dr. Tahir Mahmood, "Automatic Energy Meter Reading using Smart Energy Meter".

[12]. Poonam Borle, Ankita Saswadkar, Deepali Hiwarkar, Rupali S. Kad, "Automatic Meter Reading For Electricity Using Power Line Communication, International Journal of Advanced Research in
Electrical, Electronics and Instrumentation Engineering,Vol. 2, Issue 3,pp. 982-987,March 2013.

[13]. Manisha V Shinde, Pradip W Kulkarni, "New Development in Energy Meter Reading System”,ISSN: 2349-3371,International Journal of Scientific Research and Management Studies (IJSRMS),Volume 1 Issue 4, pp. 124-129.

[14]. RASPBERRY PI-kit https:/www.google.com/search?q=raspberry+pi+3+ model+b\%2B\&oq=raspberrypi+3+module+b\%2B\&aq $\mathrm{s}=$ chrome.1.69i57j0i13i457j0i1316.19185j0j7\&sourcei $\mathrm{d}=$ chrome\&ie=UTF-8

[15]. ENERGY METER/indiamart https://dir.indiamart.com/impcat/l-t-energymeter.html 11Smart agriculture system with IoT

[16]. Smart energy meter https://www.google.com/search?q=smart+energy+m eter\&oq=smart\&aqs=chrome. $1.69 \mathrm{i} 5912 \mathrm{j} 69 \mathrm{i} 57 \mathrm{j} 69 \mathrm{i} 59 \mathrm{j} 0$ i433j69i6013.3223j0j7\&sourceid=chrome\&ie=UTF-8

[17]. General metering tips -NFU mutual https://www.google.com/search?q=smart+energy+m eter\&oq=smart\&aqs=chrome.1.69i5912j69i57j69i59j0 i433j69i6013.3223j0j7\&sourceid=chrome\&ie=UTF-8

[18]. Smart-energy-meter https://www.iskra.eu/en/Smartenergy-meters/

[19]. Qubino smart energy meter https://qubino.com/smart-energy-meters/

[20]. Smart energy meter/IEEE https://www.engpaper.com/smart-energy-meter.htm

\section{Cite this article as :}

Md Riyad Hossain, Haimanti Biswas, Abu Raihan Dider, Dr. Sheshang Degadwala, "Design and Implementation of Smart Energy Meter System with GSM Module", International Journal of Scientific Research in Science and Technology (IJSRST), Online ISSN : 2395-602X, Print ISSN : 2395-6011, Volume 7 Issue 6, pp. 51-60, November-December 2020. Available

doi : https://doi.org/10.32628/IJSRST207423

Journal URL : http://ijsrst.com/IJSRST207423 